\title{
Increased peripheral and local soluble FGL2 in the recovery of renal ischemia reperfusion injury in a porcine kidney auto-transplantation model
}

\author{
Zitong Zhao ${ }^{1,2 \dagger}$, Cheng Yang ${ }^{1,2 \dagger}$, Long Li ${ }^{1,2 \dagger}$, Tian Zhao ${ }^{1,2}$, Lingyan Wang ${ }^{4}$, Ruiming Rong ${ }^{1,2,5}$, Bin Yang ${ }^{3 *}$,
} Ming $\mathrm{Xu}^{1,2^{*}}$ and Tongyu Zhu $\mathrm{H}^{1,2,6^{*}}$

\begin{abstract}
Background: Regulatory T cells (Treg) protect kidney against ischemia reperfusion (IR) injury via suppressing innate immunity, but the mechanism has not been fully clarified. Soluble fibrinogen-like protein 2 (sFGL2), a novel effector of Treg, may affect apoptosis and inflammation. This study investigated the role of sFGL2 in renal IR injury in a porcine kidney auto-transplantation model.

Materials and methods: The left kidney was retrieved from mini pigs and infused by University of Wisconsin solution into the renal artery with the renal artery and vein clamped for 24-h cold storage. After the right nephrectomy, the left kidney was auto-transplanted into the right for 2 weeks. 3 pigs were sacrificed at day 2, 5, 7, 10 and 14 post-transplantation respectively. Collected renal tissues and daily blood samples were stored for further analyses.

Results: Both serum creatinine and blood urea nitrogen were maximized during day 2 to 5 and followed by a gradual recovery over 2 weeks. The similar pattern were showed in histological damage, myeloperoxidase + cells and apoptosis in the kidney, as well as circulating TNF-a and IFN- $\gamma$. Serum sFGL2 presented a fluctuating increase and reached a peak at day 10. The expression of sFGL2 and its receptor FcyRIIB as well as Foxp3 and IL-10 in the kidney was notably increased from day 5 to 10.

Conclusion: The increased sFGL2 together with FCYRIIB during renal recovery after IR injury suggested that sFGL2 might be a potential renoprotective mediator involved in the renal self-repairing and remodeling in this 2-week porcine auto-transplantation model.
\end{abstract}

Keywords: Soluble FGL2, Ischemia reperfusion injury, Kidney auto-transplantation, Porcine, FcyRIIB

\footnotetext{
*Correspondence: by5@le.ac.uk; xu.ming@zs-hospital.sh.cn;

tyzhu_dr@163.com

'Equal contributors

${ }^{3}$ Transplant Group, Department of Infection, Immunity and Inflammation, University of Leicester, Leicester General Hospital, University Hospitals of Leicester, Leicester LE5 4PW, UK

'Department of Urology, Zhongshan Hospital, Fudan University; Shanghai Key Laboratory of Organ Transplantation, 180 Fenglin Road, Shanghai 200032, China

Full list of author information is available at the end of the article
} 


\section{Introduction}

Kidney transplantation serves as the best treatment for end-stage renal failure patients, although many problems related with graft and patient survival have not been solved yet. Ischemia reperfusion (IR) injury, an inevitable issue in transplantation, contributes to delayed graft function, acute and chronic rejection [1,2]. IR injury induced inflammation and apoptosis involve in both the innate and adaptive immunity, and jeopardize allograft function eventually. Regulatory T cells (Treg) were shown to protect kidney from IR injury through its immunosuppressive properties in the innate immunity [3], whereas its mechanism has not been fully clarified.

Soluble fibrinogen-like protein 2 (sFGL2) is identified as a member of fibrinogen-related protein superfamily [4]. There are two different forms of FGL2 exerting distinct properties. One is FGL2 prothrombinase, the membraneprotein form, mainly expressed on the reticuloendothelial cells and exerts procoagulative activity [5]. The other is sFGL2, the soluble form, constitutively expressed by CD4 ${ }^{+}$ and $\mathrm{CD}^{+} \mathrm{T}$ cells, while Treg cells inducibly secrete it [4]. sFGL2 works as a novel effector of Treg, demonstrating immunoregulatory function to protect against tissue injuries [6]. sFGL2 inhibited dendritic cell maturation and induced B cell apoptosis in vitro, while the downregulation of sFGL2 improved T cell proliferation, promoted Th1 cell polarization and inhibited Treg activity [7]. However, sFGL2 was recently shown contradictory properties as it promoted cellular apoptosis, such as sinusoidal endothelial cells and hepatocytes through binding to its inhibitory FcyRIIB receptor on the cell surface and led to tissue injuries [8].

In the previous study, we found that serum sFGL2 increased among renal allograft recipients with acute rejection (AR) to an extent dependent on pathological severity [9], and its secretion was induced by proinflammatory cytokines such as tumor necrosis factor (TNF) $-\alpha$ and interferon (IFN) $-\gamma$ through MAPK pathway [10]. We also discovered that sFGL2, correlated with circulating Treg in AR patients, induced tubular epithelial cell (TEC) apoptosis [11]. Apoptosis is a process of programmed cell death serving as a defense mechanism to remove unwanted and potentially dangerous cells [12]. TEC apoptosis is a double-edged sword exerting contradictory effects in distinct stages of tissue injuries, destructive in the early and protective in the late [13]. sFGL2 induces apoptosis in both inflammatory cells and TECs. Since apoptosis of different type of cells could lead to different outcomes, the final impact of sFGL2 on the kidney varies in a spatial temper manner. However, current studies of sFGL2 in the kidney are limited to its level in circulation without continuous assessments. Therefore, this study aims to further investigate local expression of sFGL2 in injured kidneys and its change trend throughout the duration of 2 weeks in a porcine kidney auto-transplantation model.

\section{Materials and methods \\ Animals}

Under the regulation laid down by the Chinese animal welfare authority and the guidelines of the Care and Use of Laboratory Animals of the Laboratory Animal Ethical Commission of Zhongshan Hospital, Fudan University, 15 male mini pigs (Bama, Guangxi, China) weighing 25$30 \mathrm{~kg}$ and between 7-8 months of age were used. They were housed with air condition, straw saw dust beds, and free access to water and fed with wetted granulated full fodder.

\section{Anesthetic protocol}

The animals were premedicated with $0.5 \mathrm{mg} / \mathrm{kg}$ of diazepam and $5 \mathrm{mg} / \mathrm{kg}$ of ketamine hydrochloride intramuscularly, followed by general anesthesia using $1 \mathrm{mg} / \mathrm{kg}$ of propofol (Fresenius Kabi, Bad Homburg, Germany) intravenously (i.v.), and maintained with a mix solution of $0.25 \mathrm{mg} / \mathrm{kg} / \mathrm{h}$ of diazepam, $2.5 \mathrm{mg} / \mathrm{kg}$ of ketamine hydrochloride, and $0.0125 \mathrm{~mL} / \mathrm{kg} / \mathrm{h}$ of compound detomidine hydrochloride or $0.5 \mathrm{mg} / \mathrm{kg} / \mathrm{h}$ of propofol i.v. in turn. The respiration was supported by a ventilator (Dräger, Lübeck, Germany) through an inserted trachea cannula. Five hundred milliliters of 5\% glucose and $0.9 \%$ sodium chloride and $500 \mathrm{~mL}$ of hydroxyethyl starch 130/0.4 and sodium chloride injection (Fresenius Kabi, Bad Homburg, Germany) were also administered i.v.. In addition, $100 \mathrm{~mL}$ of $0.3 \mathrm{~g}$ of levofloxacin lactate and 2 million units of benzylpenicillin were given i.v. $30 \mathrm{~min}$ before surgery. The same anesthetic protocol was used for donor retrieving and transplantation.

\section{Donor kidney retrieving and preservation}

The left kidney was mobilized and removed with minimal warm ischemia (about $1 \mathrm{~min}$ ) after ligating the renal artery near the abdominal aorta, renal vein near the inferior vena cava, and ureter. The isolated kidney was flushed immediately with $200 \mathrm{~mL}$ of precooled Ringer solution with $1000 \mathrm{IU}$ of heparin at $100 \mathrm{~cm} \mathrm{H}_{2} \mathrm{O}$ hydrostatic pressure until the kidney became pale and then followed by $200 \mathrm{~mL}$ of the University of Wisconsin (UW; Bristol-

Table 1 The sequences of the primers

\begin{tabular}{lll}
\hline Gene name & & Primer sequence \\
\hline GAPDH & Sense & TTCCACGGCACAGTCAA \\
& Antisense & GCAGGTCAGGTCCACAA \\
IL-10 & Sense & AGCCAGCATTAAGTCTGAGAA \\
& Antisense & CCTCTCTTGGAGCTTGCTAA \\
Foxp3 & Sense & CTCCTACTCCCTGCTGGCAAAT \\
& Antisense & CGCATGTTGGGAACTTGAAGTAGT \\
\hline
\end{tabular}



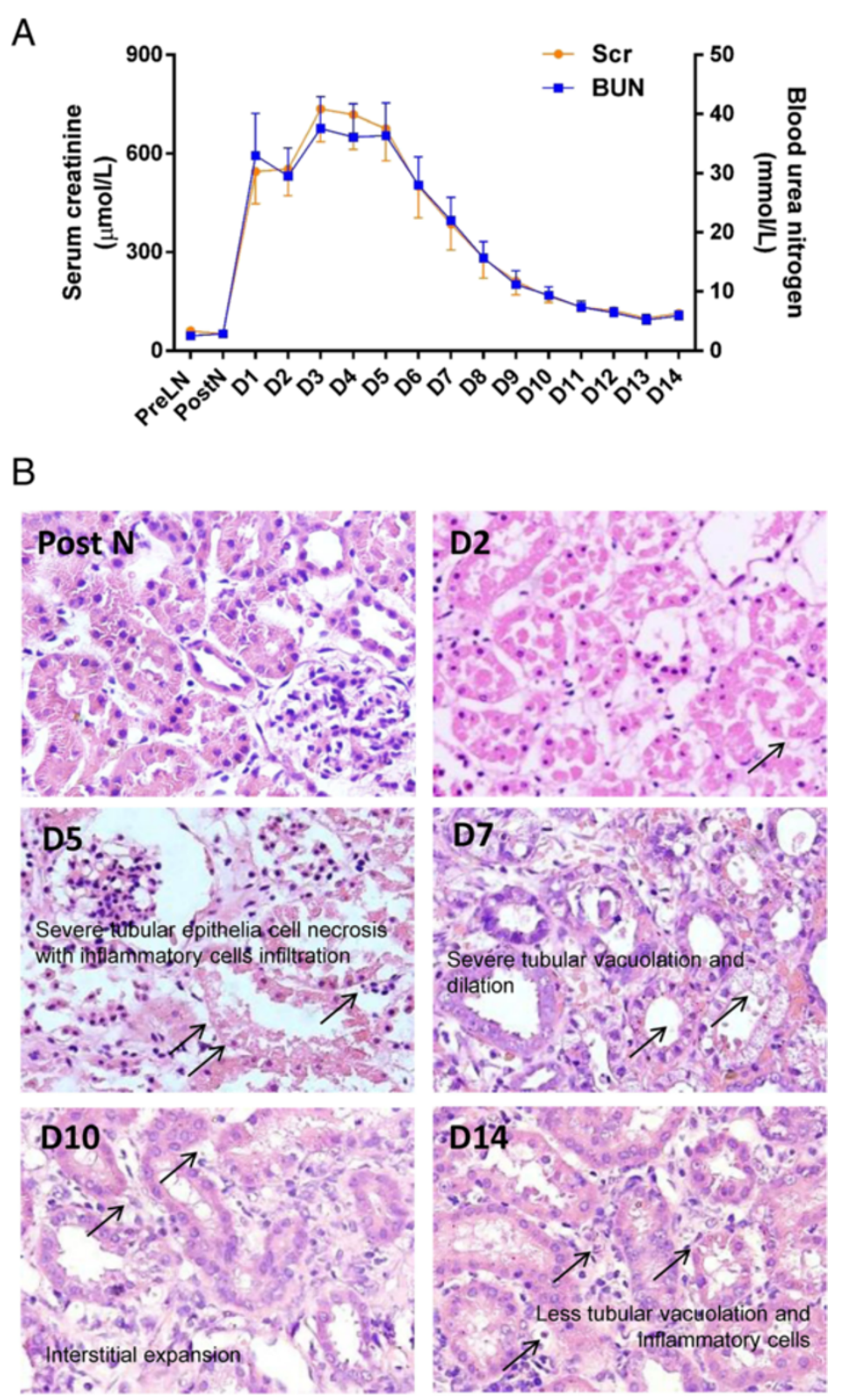

C

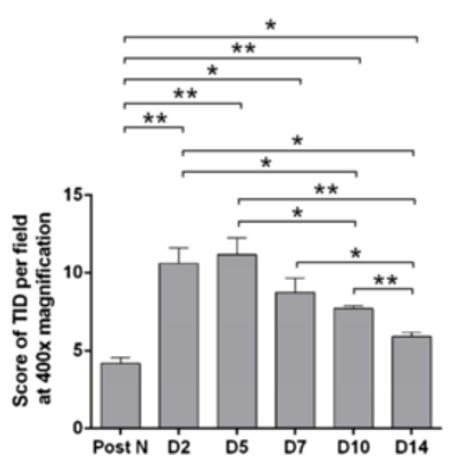

Figure 1 (See legend on next page.) 
(See figure on previous page.)

Figure 1 Renal function and renal tissue damage. Serum creatinine and urea nitrogen sharply increased at day 1 , reached a plateau at day 3 to 5 and fell close to normal at day 14 (A). Tubular vacuolation and detachment, as well as protein casts, interstitial expansion and cellular infiltration were seen in the posttranplant kidneys (B). The score of tubulointerstitial damage (TID) assessed in H\&E sections at 400× magnification showed that renal tissue damage was significantly more severe at day 2 and 5 post transplantation than post nephrectomy, marginally better at day 7, followed by gradual recovery at day 10 and $14 \mathbf{( C )}$. Data are expressed as mean \pm SEM $(n=3)$. Pre LN: pre left nephrectomy; Post N: post nephrectomy. *: $P<0.05 ;{ }^{* *}: P<0.01$.

Myers Squibb, New York, USA) solution. The kidney was preserved in the Steri-Drape (3 M Health Care, St. Paul, USA) with the iced UW solution at $4^{\circ} \mathrm{C}$ for $24 \mathrm{~h}$.

\section{Right nephrectomy and auto-transplantation}

Next day, the right kidney was resected after ligating the right renal artery and vein, as well as the ureter, close to the renal hilum. The left kidney was orthotopically autotransplanted into the right. In addition, a double lumen cuffed silicone vascular access catheter (Arrow International, Reading, PA, USA) was placed in the left internal jugular vein. The lumens of the central line were fixed behind the ear and blocked with heparin.

During the period of 2 weeks, blood samples were taken daily. Three pigs were anaesthetized and sacrificed for the graft harvest at day 2, 5, 7, 10 and 14 post transplantation respectively. The right post-nephrectomy kidney was used as the normal control. The part of renal tissues was fixed with $10 \%$ buffered formalin for histological examination and the others were snapping frozen for molecular biological analyses.

\section{Histological assessment}

The renal histological damage was assessed in Hematoxylin and Eosin (H\&E) stained sections by three researchers blinded to the coding. The semi-quantitative score system was comprised of four criteria including loss of tubular epithelium, tubular vacuolation and nuclear loss, protein casts and interstitial expansion caused by oedema and/or cellular infiltration. Each criterion was graded from mild to severe by the percentage of injury: $0(<1 \%) ; 1(1-25 \%)$; 2 (26-50\%); 3 (51-75\%) and $4(>75 \%)$.

\section{The serum level of sFGL2, TNF- $\alpha$ and IFN- $\gamma$}

Peripheral blood samples were centrifuged at $4^{\circ} \mathrm{C}$, $2500 \mathrm{rpm}$, for $25 \mathrm{~min}$ to obtain the serum. The serum level of sFGL2 was detected in duplicate using an enzymelinked immunosorbent assay (ELISA) kit (Biolegend, San Diego, USA). The serum level of TNF- $\alpha$ and IFN- $\gamma$ were also assessed in duplicate using ELISA kits (BD Biosciences, San Diego, USA). All experimental procedures were performed according to the manufacturer's instructions. The final concentration was determined using a standard curve.
In situ end-labelling (ISEL) apoptotic cells

Paraffin sections were used for ISEL fragmented DNAs with digoxigenin-deoxyuridine (dUTP) by terminal deoxynucleotidyl transferase (TdT) using an Apoptosis Detection Kit (Millipore, Billerica, USA). Briefly, the sections were digested by $40 \mu \mathrm{g} / \mathrm{ml}$ proteinase $\mathrm{K}$ for $15 \mathrm{~min}$ at $37^{\circ} \mathrm{C}$, incubated with TdT and digoxigenin-dUTP at $37^{\circ} \mathrm{C}$ for $60 \mathrm{~min}$ and transferred to wash/stop buffer for $30 \mathrm{~min}$. After adding anti-digoxigenin-peroxidase complex for $30 \mathrm{~min}$, these sections were developed by AEC substrate. Apoptotic cells were examined at 400x magnification for 20 fields in tubulointerstitial areas.

\section{Immunostaining for myeloperoxidase (MPO), active caspase-3, sFGL2 and FcyRIIB}

For antigen retrieval, paraffin sections were digested by the same method with ISEL for MPO, or using $10 \mathrm{mM}$ sodium citrate buffer for active caspase-3, sFGL2 and FcyRIIB. The sections were then blocked by peroxidaseblocking reagent and labelled by anti-MPO (1:600 dilution, DAKO), anti-active caspase- 3 antibody (1:100 dilution, R\&D System, Minnesota, USA), anti-sFGL2 (1:200 dilution, Abcam, Cambridge, UK) or anti-FcyRIIB (1:200 dilution, Abcam) antibodies at $4{ }^{\circ} \mathrm{C}$ overnight. The antibody binding was revealed by AEC for MPO and active caspase-3, and DAB for sFGL2 and FcyRIIB. MPO + cells and active caspase-3+ cells in the renal cortex were manually counted, while the expression of sFGL2 and Fc $\gamma$ RIIB were semi-quantitatively scored using optical volume density $\left(\mathrm{OD} \times \mathrm{mm}^{2}\right)$ analysis (Image-Pro Plus 6.0, Media Cybernetics Inc., Bethesda, USA) in 20 fields at $400 \times$ magnification.

\section{Protein expression assay by western blotting}

Twenty $\mu$ g protein from kidney homogenate was separated on $15 \%$ (wt/vol) poly acrylamide denaturing gels and electro-blotted onto Hybond-C membranes. These membranes were blocked with $5 \%$ (wt/vol) milk, separately probed with anti-active caspase-3 (1:1,000 dilution, Cell Signaling Technology, Boston, USA), anti-soluble FGL2 (1:10,000 dilution, Abcam) or anti-FcyRIIB (1:10,000 dilution, LifeSpan BioSciences, Seattle, USA) antibody. For the loading control, the same membranes were probed with anti- $\beta$-actin antibody (1:10,000 dilution, Abcam), and then incubated with peroxidase-conjugated secondary antibodies (1:10,000 dilution, Jackson ImmunoResearch, West Grove, 

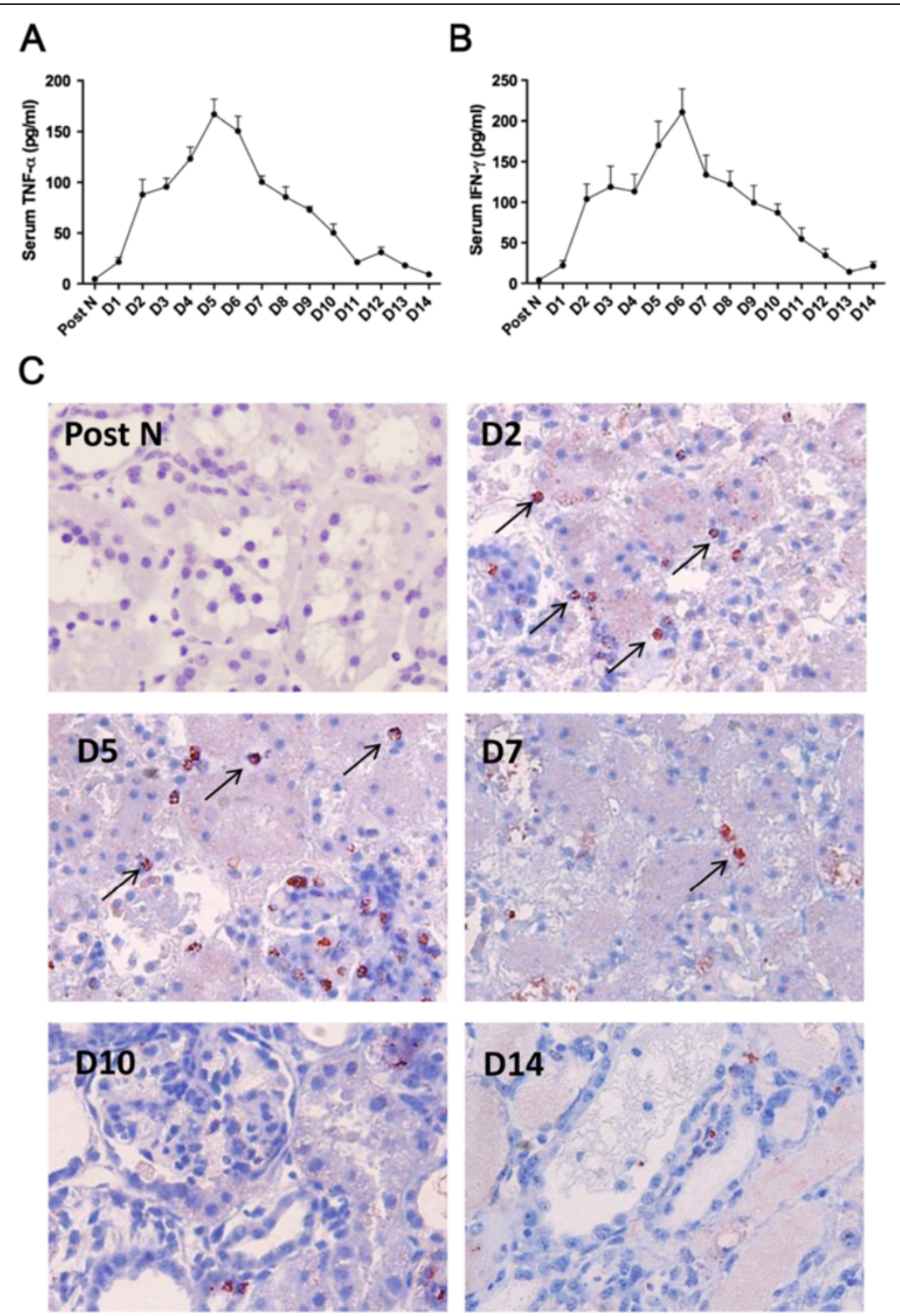

D

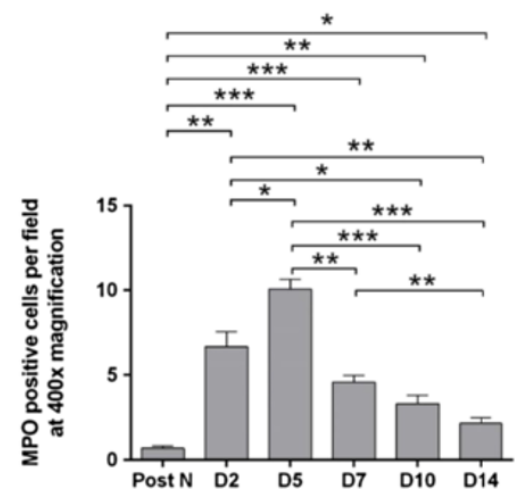

Figure $\mathbf{2}$ (See legend on next page.) 
(See figure on previous page.)

Figure $\mathbf{2}$ Inflammation in the peripheral blood and kidney. The serum level of TNF-a (A) and IFN- $\gamma$ (B) showed a stable increase after transplantation, a summit at day 5 and a gradual decrease thereafter. Immunohistochemistry staining at 400x magnification displayed that MPO + cells scattered in the posttransplant kidneys, mostly in vascular lumens and interstitial areas and some also in glomerular areas, or penetrating through tubular areas (C). The number of MPO + cells markedly increased from day 2, culminated at day 5 and notably reduced since day 7 till day 14 (D). Data are expressed as mean \pm SEM $(n=3)$. Post N: post nephrectomy. $*: P<0.05 ;{ }^{* *}: P<0.01 ;{ }^{* * *}: P<0.001$.

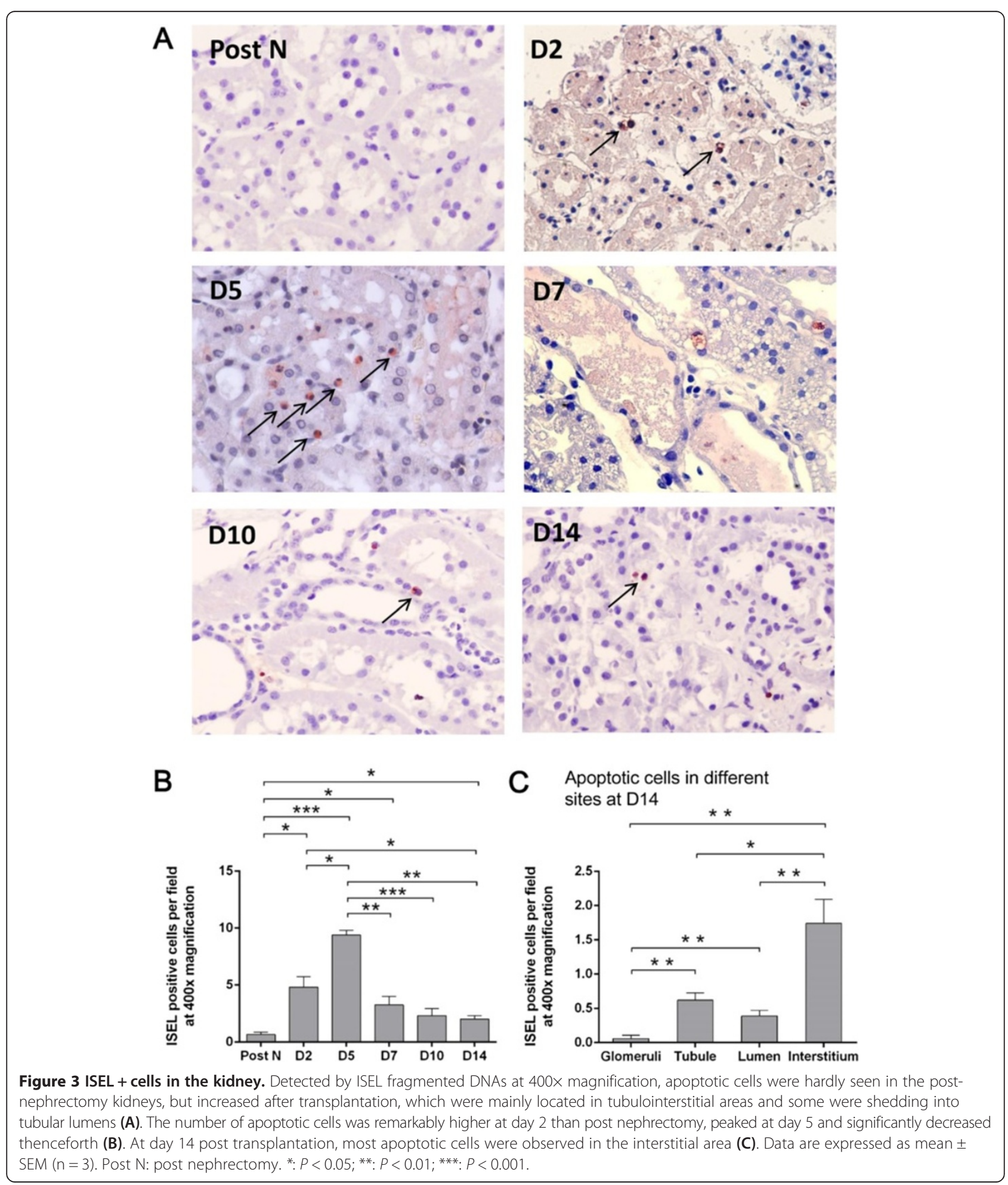



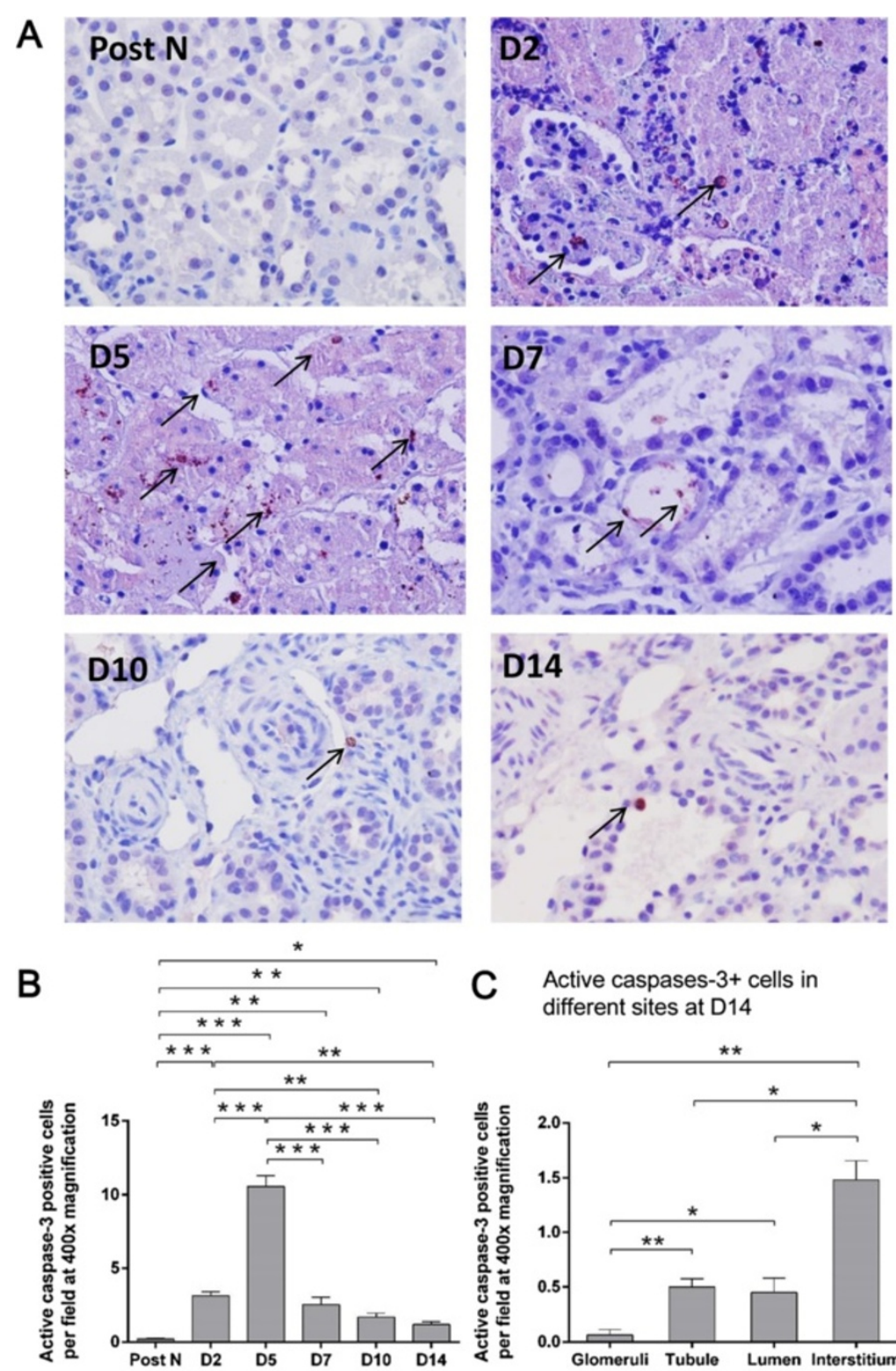

Active caspases-3+ cells in
different sites at D14

D

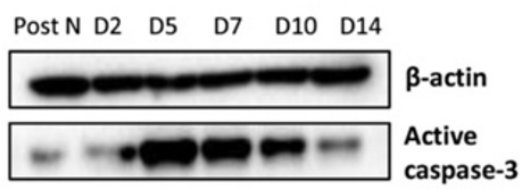

E
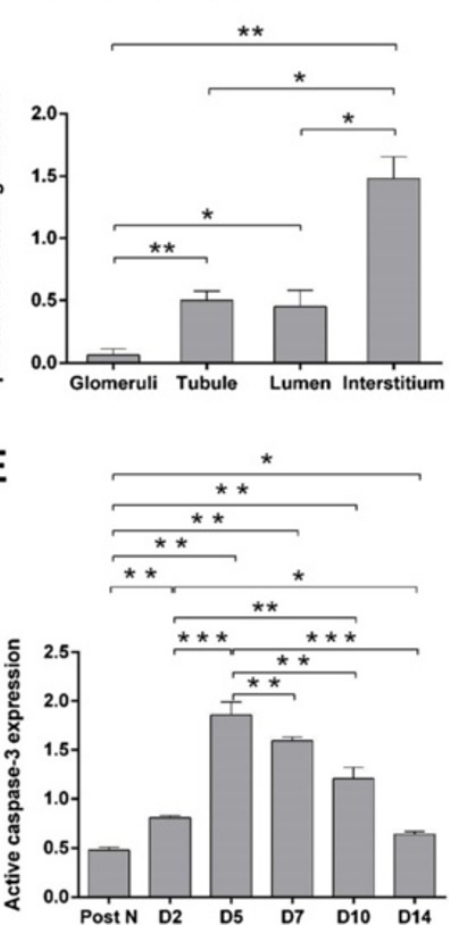

Figure 4 (See legend on next page.) 
Figure 4 Active caspase-3 expression in the kidney. Active caspase-3+ apoptotic cells were increased post-transplantation, mainly located in the tubule and tubulointerstitial area with some shedding into tubular lumens (A). The number of active caspases-3+ cells was significantly higher at day 2 than post nephrectomy, peaked at day 5 and remarkably decreased thenceforth (B). Similar to ISEL + cells, most active caspase-3+ cells were observed in the interstitial area at day 14 post transplantation $\mathbf{( C )}$. Accordingly, the protein expression of active caspase-3 was consistent with its immunostaining results (D-E). Data are expressed as mean \pm SEM $(n=3)$. Post N: post nephrectomy. ${ }^{*}: P<0.05 ;{ }^{* *}: P<0.01 ;{ }^{* * *} P<0.001$.

USA) at room temperature for $1 \mathrm{~h}$. Immunoreactive bands were visualized using ECL substrate (Thermo Fisher Scientific, Rockford, USA) and a Bio-Image Analysis System (Cell Biosciences, Inc., Santa Clara, USA). The semi-quantitative analysis results were expressed as optical volume density $\left(\mathrm{OD} \times \mathrm{mm}^{2}\right)$ and normalized by $\beta$-actin for loading (AlphaView Software 3.3, Cell Biosciences, Inc.).

\section{Foxp3 and IL-10 mRNA expression}

Total RNA was extracted from renal tissues with Trizol reagent (Invitrogen, Carlsbad, USA). One $\mu \mathrm{g}$ of total RNA was transcribed into cDNA using a RevertAid ${ }^{\mathrm{TM}}$ First Strand cDNA Synthesis Kit (Fermentas, Glen Burnie, USA). Realtime quantitative PCR (qPCR) was performed using the SYBR Premix Ex Taq Kit (Takara Bio Inc., Otsu, Japan) in a MasterCycler RealPlex4 system (Eppendorf, Hamburg, Germany). After a hot start $\left(30\right.$ seconds at $\left.95^{\circ} \mathrm{C}\right)$, amplification was performed for 45 cycles $\left(5\right.$ seconds at $95^{\circ} \mathrm{C}$, 30 seconds at $55^{\circ} \mathrm{C}, 60$ seconds at $72^{\circ} \mathrm{C}$ ). The primers were listed in Table 1 . The expression of mRNA normalized with GAPDH were calculated against control kidneys (Post N) using a $2^{-\Delta \Delta \mathrm{Ct}}$ method.

\section{Statistical analysis}

Results are expressed as mean \pm standard error of the mean (SEM). Normality tests were carried out. One-way ANOVA was used for statistics, and post hoc comparisons were then performed by Scheffe test using SPSS 18.0 software (SPSS Inc, Armonk, USA). P values $<0.05$ were considered to be statistically significant.

\section{Results}

\section{Renal function and histological damage}

Serum creatinine (Scr) and blood urea nitrogen (BUN) were examined before left nephrectomy and daily over 14 days after auto-transplantation. The level of both Scr and BUN sharply increased at day 1 , reached a plateau at day 3 to 5 , fell off gradually thereafter and closed to the normal level at day 14 (Figure 1A).

The tubulointerstitial damage (TID) was assessed in $H \& E$ stained sections of the grafts harvested at day 2, 5, 7, 10 and 14 post-transplantation. Compared with the normal tissue from right nephrectomy, there were lots of tubular vacuolation and detachment, as well as protein casts, interstitial expansion and cellular infiltration in the post-tranplant kidneys at day 2 and 5. TID became less severe at day 7 and 10, but mild tubular dilation and interstitial expansion were still seen at day 14 (Figure 1B). The semi-quantitative analysis revealed that TID was significantly more severe at day 2 and 5 post-transplantation than normal tissue from postnephrectomy, marginally better at day 7 , followed by a gradual recovery from day 10 to 14 (Figure $1 \mathrm{C}$ ).

\section{Inflammation in the circulation and kidney}

To investigate the profile of systemic inflammatory responses in vivo during the processes of injury and recovery, the serum level of pro-inflammatory cytokines TNF- $\alpha$ and IFN- $\gamma$, as well as neutrophils infiltration in the kidney, was detected. The similar trends were shown as renal function with continuous increase post transplantation, a summit at day 5 or day 6 and a gradual decrease thenceforth (Figure 2A-B).

The MPO + cells in the kidney were scattered in the post-transplant kidneys, mostly in vascular lumens and interstitial areas and some also in glomerular areas, or penetrating through tubular areas (Figure 2C). The number of $\mathrm{MPO}+$ cells was markedly increased from day 2, culminated at day 5 and notably reduced since day 7 till day 14 (Figure 2D).

\section{Apoptotic cells in the kidney}

Apoptosis also represents the degree of renal allograft injury after transplantation. Therefore, the number of apoptotic cells was detected in the kidney using ISEL and active caspase-3 labeling. Apoptotic cells were hardly seen in the post-nephrectomy kidneys, but increased after transplantation, which were mainly located in tubulointerstitial areas and some were shedding into tubular lumens (Figures 3A and 4A). The dynamic change in the number of apoptotic cells within 2 weeks resembled that of MPO + cells, which was remarkably higher at day 2 than post nephrectomy, peaked at day 5 and significantly decreased thereafter (Figures 3B and 4B). It was interesting that most apoptotic cells were observed in the interstitial area rather than the glomerular, tubular or lumen areas at day 14 after transplantation, when the renal structural reconstruction and recovery were dominant (Figures $3 \mathrm{C}$ and $4 \mathrm{C}$ ). The protein expression of active caspase- 3 was in accordance with its immunostaining results, except that relative higher levels were seen from day 7 to 14 , which might be due to higher sensitivity of western blotting compared to immunostaining (Figure 4D-E). 

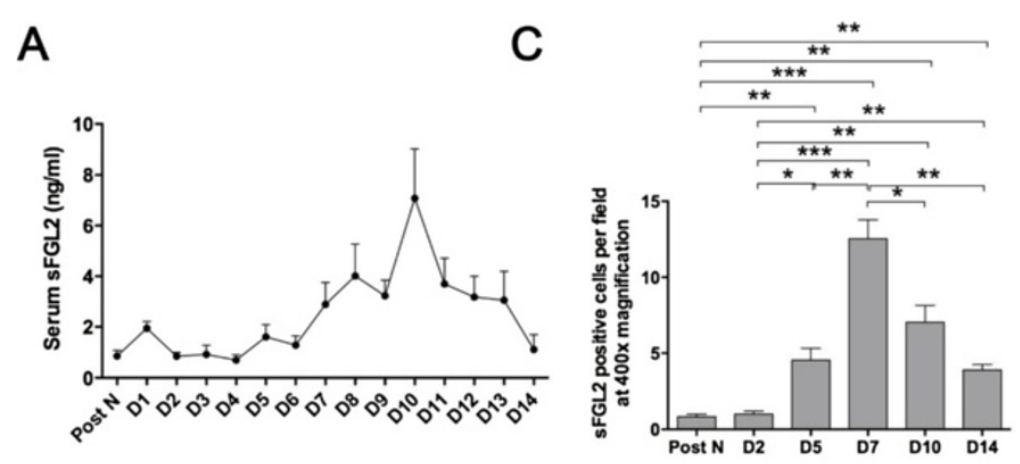

B
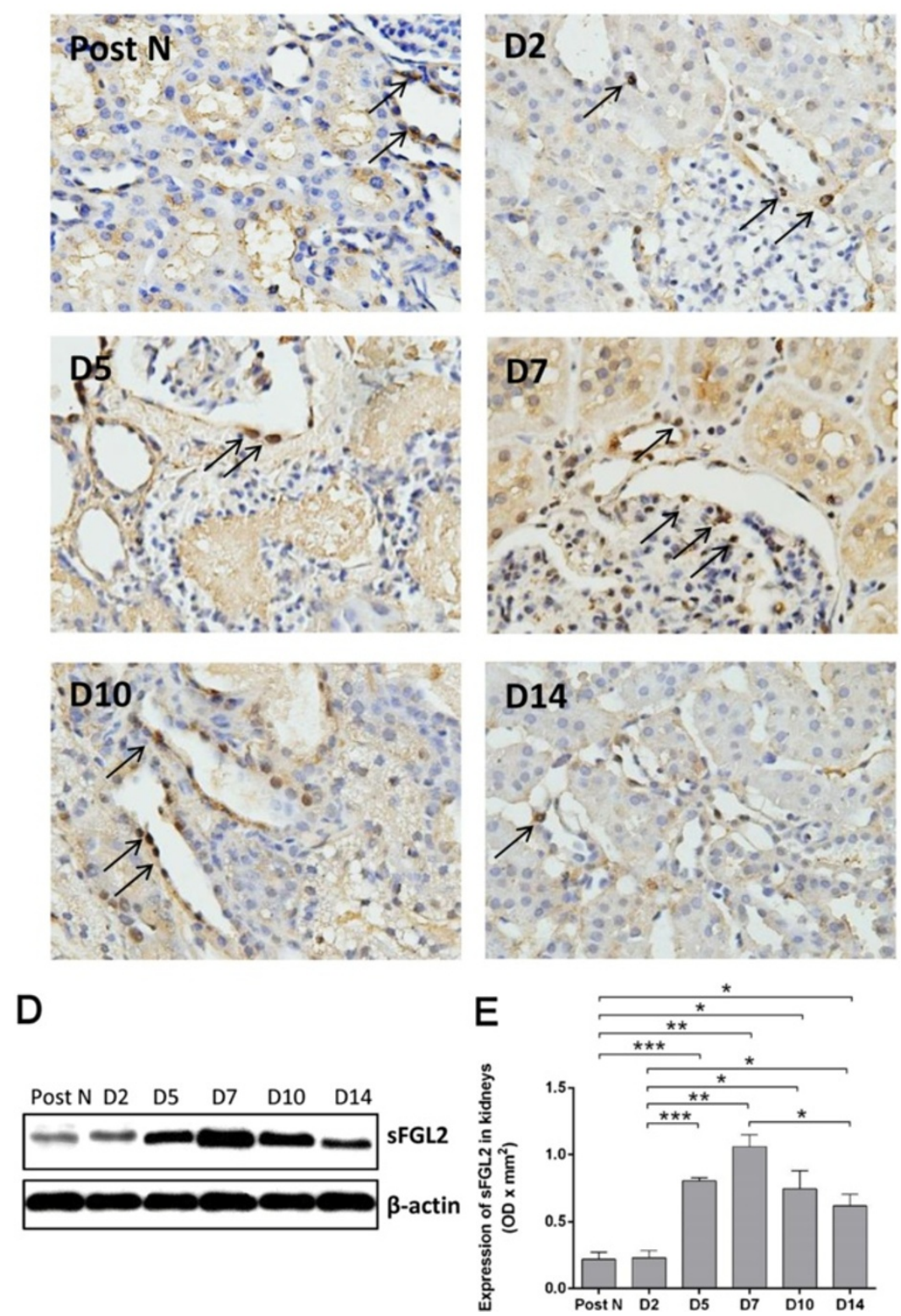

Figure 5 (See legend on next page.) 
Figure 5 The peripheral and local expression of sFGL2. Serum sFGL2 presented a fluctuating increase after transplantation, reached the peak at day 10 and gradually fell off eversince (A). Immunohistochemistry staining at 400x magnification showed that sFGL2 positive cells included TECs, interstitial cells and a few in the glomeruli (B). The number of sFGL2 positive cells in the kidney (C) and western blotting (D-E) revealed that there was no significant difference in the expression of sFGL2 between normal renal tissue and that of day 2 post transplantation. sFGL2 in the kidney remarkably increased from day 5, culminated at day 7 and gradually decreased at day 10 and 14 . Data are expressed as mean \pm SEM $(n=3)$. Post N: post nephrectomy. ${ }^{*}: P<0.05$; $^{* *}: P<0.01 ;{ }^{* *}: P<0.001$.

\section{sFGL2 expression in the circulation and kidney}

The level of sFGL2 in the peripheral blood was detected by ELISA. Serum sFGL2 presented a fluctuating increase after transplantation, reached the peak at day 10 and gradually decreased thereafter (Figure 5A). The localization and expression of sFGL2 in the kidney were determined by immunohistochemistry staining and western blotting. Different kinds of sFGL2 positive cells by immunohistochemistry staining were observed including TECs and other cells in the interstitial or glomeruli area, which represented the secreting cells or the target cells of sFGL2 (Figure 5B). There was no significant difference in the expression of sFGL2 between the normal tissues and that of day 2 post-transplantation. sFGL2 in the kidney remarkably increased from day 5, culminated at day 7 and gradually decreased at day 10 and 14 (Figure 5C-E).

\section{FcyRIIB expression in the kidney}

Since the significant change of sFGL2 in the kidney autograft was observed, the localization and quantity of FcyRIIB in the kidneys were subsequently examined. FC $\mathrm{RIIB}$, the receptor of sFGL2, was mainly displayed on TECs, showing the main target of sFGL2 (Figure 6A). The change trend of FcyRIIB during 2 weeks posttransplantation was analogous to that of sFGL2. After a slight low expression at day 2, FcyRIIB was significantly risen from day 5 , followed by a peak at day 7 and a subsequent decrease at day 10 and 14 (Figure 6B-D). The synchronical change of sFGL2 and its receptor FcyRIIB further testified the hypothesis that sFGL2 was involved in the recovery of renal IR injury.

\section{Foxp3 and IL-10 expression in the kidney}

Based on the dynamic changes of sFGL2 throughout 2 weeks of renal ischemia reperfusion injury, its secreting cells, Tregs, were further examined by the expression of representing Foxp3 and IL-10 in the kidney. Both Foxp3 and IL-10 mRNA in the kidney remarkably increased from day 5, culminated at day 7 and gradually decreased at day 10 and 14 (Figure 7A-B), with a trend similar to that of sFGL2 expression in the kidney.

\section{Discussion}

Our serial in vivo and in vitro studies showed that circulating sFGL2 was increased in kidney injuries and contributed to TEC apoptosis [11]. Here, we further investigated the dynamic change of sFGL2 in the kidney and circulation throughout 2-week duration of renal IR injury in a porcine auto-transplantation model. This study revealed that renal dysfunction and histological damage was maximized from day 2 to 5 post-transplantation and followed by a gradual recovery, while the expression of sFGL2 and its receptor FCyRIIB exhibited a delayed peak at day 5 to 10 . These results indicate that sFGL2 might be involved in the process of renal repairing and remodeling and exert protective effects.

sFGL2, as an immunoregulatory effector of Treg, has been proved a capacity of TEC apoptotic induction. TECs compromise over $80 \%$ of renal parenchymal cells and play an important role in maintaining normal kidney function [14]. TEC apoptosis is closely related with IR injury, delayed graft function and early allograft survival [15]. It was shown that TEC apoptosis occurs in two distinct phases of kidney injuries. The first one occurs early on 12 to $48 \mathrm{~h}$ after the injury, during which TEC apoptosis leads to tubular cell loss and tubular dysfunction. Whereas the second phase occurs days later in the recovery process, with TEC apoptosis postulated to contribute to the remodeling of injured tubules and to facilitate their return to a normal structural and functional state [13]. Although raised TNF- $\alpha$ and IFN- $\gamma$ in the early renal IR injury could promote sFGL2 production, the delayed peak of sFGL2 at the recovery stage was likely to be further facilitated by other causes apart from these two pro-inflammatory factors. TEC apoptosis at the early stage of renal injury is possibly due to other factors but sFGL2.

Apoptosis is a complex process involving multiple factors, among which TNF- $\alpha$ is a typical apoptosis-inducing mediator [16]. There are two broad pathways leading to apoptosis, the extrinsic and intrinsic pathways [17]. The extrinsic apoptosis indicates a form of death induced by extracellular signals that result in the binding of ligands, such as TNF- $\alpha$, to specific trans-membrane receptors, collectively known as death receptors belong to the TNF superfamily, and recruiting the down-stream adaptor proteins. The intrinsic apoptosis, on the other hand, is activated in response to a number of stressing conditions, converges on the mitochondria and leads to the release of cytochrome $\mathrm{C}$. In both pathways, signaling results in the activation of a family of cysteine proteases, named 
A
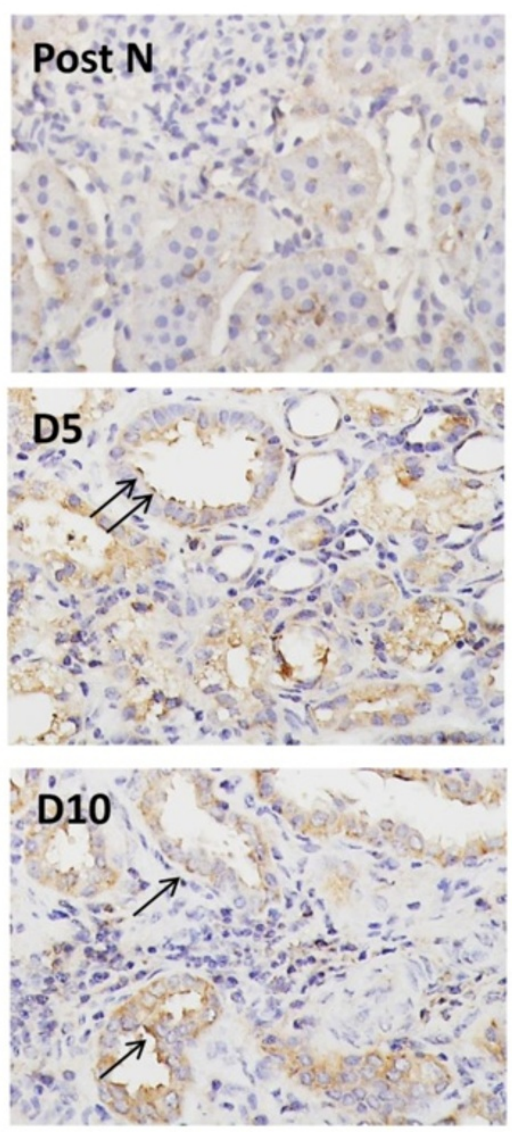

B

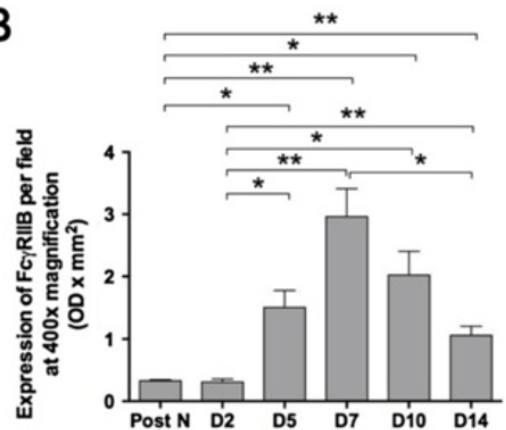

C

$\begin{array}{lllll}\text { Post N D2 D5 } & \text { D7 } & \text { D10 } & \text { D14 }\end{array}$

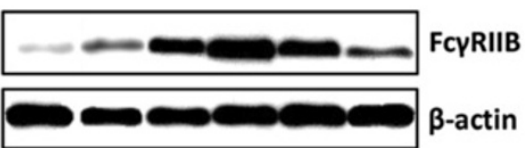

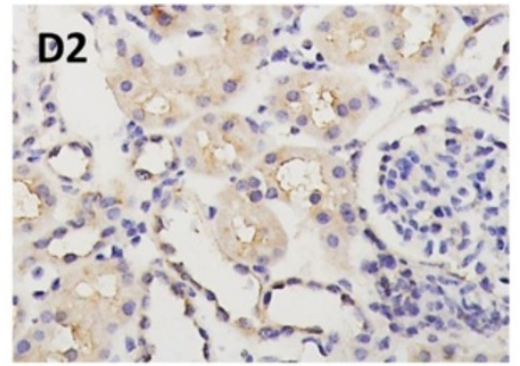
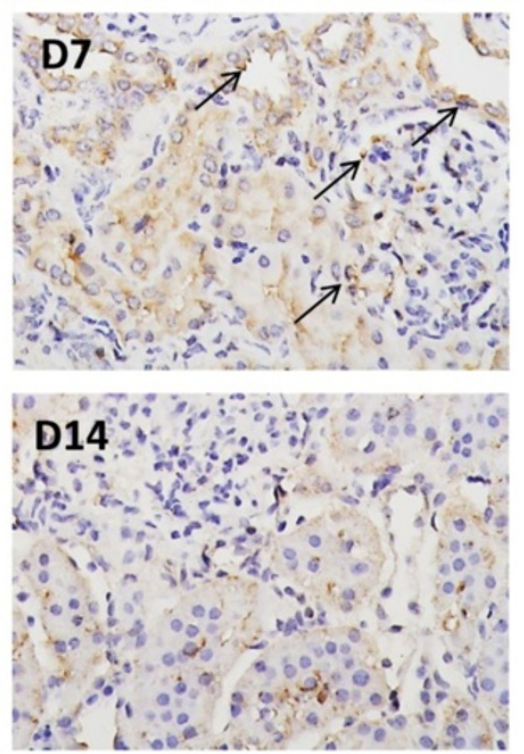
(See figure on previous page.)

Figure 6 FcyRIIB expression in the kidney. Immunohistochemistry staining at 400x magnification revealed that FcyRIIB, the receptor of sFGL2, focused on TECs (A). The number of FcyRIIB positive cells in the kidney (B) and western blotting (C-D) showed that after a slight shift at day 2, FCyRIIB significantly rose from day 5 , followed by a peak at day 7 and a subsequent decrease at day 10 and 14 . Data are expressed as mean \pm SEM $(\mathrm{n}=3)$. Post N: post nephrectomy. * $P<0.05$; $^{* *}: P<0.01{ }^{* * * *}: P<0.001$.

caspases, which acts in a proteolytic cascade to dismantle and remove the dying cells. This study showed the strikingly increase of TNF- $\alpha$ together with the maximized TEC apoptosis, renal function and tissue damage at day 5 , indicating a link and cascade events among them, as well as a contribution of TEC apoptosis to the loss of renal function.

Moreover, apoptotic cells, featured with nuclear and cytoplasmic condensation, followed by plasma membrane blebbing and releasing apoptotic bodies, are rapidly identified by neighboring cells or professional phagocytes and dispose generally without induction of inflammation [18]. The slight increase of sFGL2 at the peak of renal IR injury probably initiates renal recovery by inducing apoptosis in inflammatory cells in the interstitial area and limiting inflammation expansion. Taken together, the change trend of MPO + cells with a peak at day 5 and a subsequent decrease, consistent with that of circulating pro-inflammatory cytokines, was linked to the severity changes of renal injury in terms of renal function and tubulointerstitial damage throughout 2week post auto-transplantation. Most porcine kidney auto-transplantation studies vary in modeling duration and renal recovery pattern. In a UW-preserved 7-day porcine kidney auto-transplantation [19], renal function continuously deteriorated till day 7 , while its only histology assessment at day 7 might limited the knowledge of kidney responses in between. In another 10-week study with similar modeling to ours [20], the peak of renal IR injury was at 2 to 4 days as well followed by gradual renal function recovery. However, compared to its one-time intra-operative biopsy showing early reperfusion injury, our study exhibited a more comprehensive inflammatory and apoptosis trend in the kidney throughout 2-week duration. The wide variations among studies might be owing to different surgical techniques and perioperative care.

Most interestingly, the highest level of sFGL2 during a period of 2-week auto-transplantation appeared approximately 2 to 5 days later than that of renal function and histological damage, as well as inflammation and apoptosis. It is recently demonstrated that Treg modulate renal IR injury through IL-10-mediated blockade of innate immune cell activation and accumulation [6]. The data from this study indicate that the enhanced injury might trigger the process of repairing and remodeling, which was marked by the increased expression of sFGL2. The consistent changes of sFGL2 and its receptor FcyRIIB with Foxp3 and IL-10, representative of Treg cells, throughout 2 weeks reveal that our study provides sFGL2 as another potential mechanism of Treg protecting renal IR injury. Undoubtedly, further intervention researches are needed to further support our hypothesis. Moreover, the expression of sFGL2 in the kidney peaked at day 7 while its serum level at day 10, probably owing to the initial great transfer of circulating sFGL2 into the kidney for recovery but less convey after its renoprotection fulfilled. Apparently, activated Treg recruited to the injured kidney and secreting large amounts of sFGL2 locally at the beginning of renal recovery is also a likely explanation.

In conclusion, our findings provide a new insight into renal IR injury throughout 2 -week duration in a porcine kidney auto-transplantation model. Taken together with the 2-week inflammatory and apoptosis trend in renal ischemia reperfusion injury, the continuous assessment
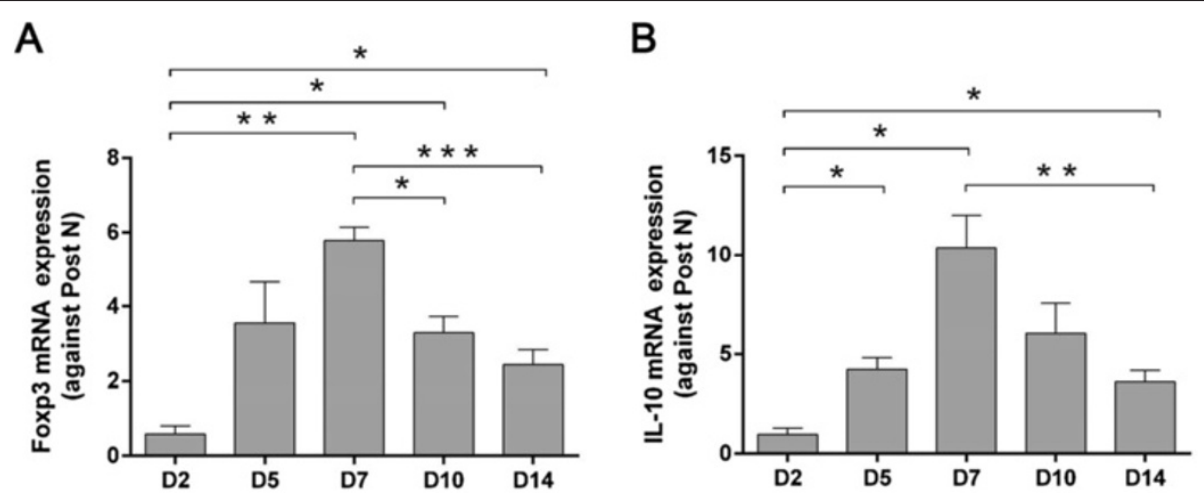

Figure 7 Foxp3 and IL-10 mRNA expression in the kidney. Both Foxp3 and IL-10 mRNA in the kidney remarkably increased from day 5, culminated at day 7 and gradually decreased at day 10 and 14 (A-B). Data are expressed as mean \pm SEM $(n=3)$. *: $P<0.05$; **: $P<0.01$; ***: $P<0.001$. 
of sFGL2 expression in the peripheral blood and renal tissues reveals the potential involvement of sFGL2 in renoprotection as a novel mechanism. However, the direct sFGL2-dependent effect of Treg in attenuating renal injuries needs to be further investigated.

\section{Competing interests}

The authors have declared no competing interests.

\section{Authors' contributions}

$Z Z$ and YC conceived of the study, and participated in the design of the study and performed the statistical analysis. YC, LL, ZT and XM carried out the animal surgery. $L L$ and $W L$ performed the pathological and molecular studies. ZZ and YC drafted the manuscript. YB participated in the design of the study and revised the manuscript. RR participated in the statistical analysis. XM and ZT provided the fund support. All authors read and approved the final manuscript.

\section{Acknowledgements}

This study was supported by National Natural Science Foundation of China (81270832, 81270833 and 81370852) and Science and Technology Commission of Shanghai Municipality (12ZR1405500). The authors thank Jianying Shi from Shanghai Medical College, Fudan University for expert renal pathological assessment.

\section{Author details}

'Department of Urology, Zhongshan Hospital, Fudan University; Shanghai Key Laboratory of Organ Transplantation, 180 Fenglin Road, Shanghai 200032, China. ${ }^{2}$ Shanghai Key Laboratory of Organ Transplantation, 180 Fenglin Road, Shanghai 200032, China. ${ }^{3}$ Transplant Group, Department of Infection, Immunity and Inflammation, University of Leicester, Leicester General Hospital, University Hospitals of Leicester, Leicester LE5 4PW, UK. ${ }^{4}$ Biomedical Research Center, Zhongshan Hospital, Fudan University, Shanghai 200032, China. ${ }^{5}$ Department of Transfusion, Zhongshan Hospital, Fudan University, Shanghai, China. ${ }^{6}$ Qingpu Branch Zhongshan Hospital, Fudan University, 1158 Gongyuan Road East, Shanghai 201700, China.

Received: 31 October 2013 Accepted: 19 February 2014

Published: 23 February 2014

\section{References}

1. Nankivell BJ, Kuypers DR: Diagnosis and prevention of chronic kidney allograft loss. Lancet 2011, 378:1428-1437.

2. Ojo AO, Wolfe RA, Held PJ, Port FK, Schmouder RL: Delayed graft function: risk factors and implications for renal allograft survival. Transplantation 1997, 63:968-974.

3. Kinsey GR, Sharma R, Huang L, Li L, Vergis AL, Ye H, Ju ST, Okusa MD: Regulatory $T$ cells suppress innate immunity in kidney ischemiareperfusion injury. J Am Soc Nephrol 2009, 20:1744-1753.

4. Marazzi S, Blum S, Hartmann R, Gundersen D, Schreyer M, Argraves S, von Fliedner V, Pytela R, Ruegg C: Characterization of human fibroleukin, a fibrinogen-like protein secreted by T lymphocytes. J Immunol 1998, 161:138-147.

5. Yuwaraj S, Ding J, Liu M, Marsden PA, Levy GA: Genomic characterization, localization, and functional expression of FGL2, the human gene encoding fibroleukin: a novel human procoagulant. Genomics 2001, 71:330-338.

6. Shevach EM: Mechanisms of foxp3+ T regulatory cell-mediated suppression. Immunity 2009, 30:636-645.

7. Chan CW, Kay LS, Khadaroo RG, Chan MW, Lakatoo S, Young KJ, Zhang L, Gorczynski RM, Cattral M, Rotstein O, Levy GA: Soluble fibrinogen-like protein 2/fibroleukin exhibits immunosuppressive properties: suppressing T cell proliferation and inhibiting maturation of bone marrow-derived dendritic cells. J Immunol 2003, 170:4036-4044.

8. Selzner N, Liu H, Boehnert MU, Adeyi OA, Shalev I, Bartczak AM, Xue-Zhong M, Manuel J, Rotstein OD, McGilvray ID, Grant DR, Phillips MJ, Levy GA, Selzner M: FGL2/fibroleukin mediates hepatic reperfusion injury by induction of sinusoidal endothelial cell and hepatocyte apoptosis in mice. J Hepatol 2012, 56:153-159.
9. Zhao Z, Yang C, Tang Q, Zhao T, Jia Y, Ma Z, Rong R, Xu M, Zhu T: Serum level of soluble fibrinogen-like protein 2 in renal allograft recipients with acute rejection: a preliminary study. Transplant Proc 2012, 44:2982-2985.

10. Zhao Z, Wang L, Yang C, Zhao T, Li L, Hu L, Wu D, Rong R, Xu M, Zhu T: Soluble FGL2 induced by tumor necrosis factor-alpha and interferongamma in CD4(+) T cells through MAPK pathway in human renal allograft acute rejection. J Surg Res 2013, 184:1114-1122.

11. Zhao Z, Yang C, Wang L, Li L, Zhao T, Hu L, Rong R, Xu M, Zhu T: The regulatory $T$ cell effector soluble fibrinogen-like protein 2 induces tubular epithelial cell apoptosis in renal transplantation. Exp Biol Med (Maywood) 2014, 239(2):193-201.

12. Estaquier J, Vallette F, Vayssiere $J \mathrm{~L}$, Mignotte B: The mitochondrial pathways of apoptosis. Adv Exp Med Biol 2012, 942:157-183.

13. Lieberthal W, Koh JS, Levine JS: Necrosis and apoptosis in acute renal failure. Semin Nephrol 1998, 18:505-518.

14. Du C, Guan Q, Yin Z, Masterson M, Zhong R, Jevnikar AM: Renal tubular epithelial cell apoptosis by Fas-FasL-dependent self-injury can augment renal allograft injury. Transplant Proc 2003, 35:2481-2482.

15. Oberbauer R, Rohrmoser M, Regele H, Muhlbacher F, Mayer G: Apoptosis of tubular epithelial cells in donor kidney biopsies predicts early renal allograft function. J Am Soc Nephrol 2006-2013, 1999:10.

16. Guan Q, Nguan CY, Du C: Expression of transforming growth factor-beta1 limits renal ischemia-reperfusion injury. Transplantation 2010, 89:1320-1327

17. Favaloro B, Allocati N, Graziano V, Di llio C, De Laurenzi V: Role of apoptosis in disease. Aging (Albany NY) 2012, 4:330-349.

18. Wong RS: Apoptosis in cancer: from pathogenesis to treatment. J Exp Clin Cancer Res 2011, 30:87.

19. Schreinemachers MC, Doorschodt BM, Florquin S, van den Bergh Weerman MA, Reitsma JB, Lai W, Sitzia M, Minor TM, Tolba RH, van Gulik TM: Improved preservation and microcirculation with POLYSOL after transplantation in a porcine kidney autotransplantation model. Nephrol Dial Transplant 2009, 24:816-824.

20. Snoeijs MG, Matthijsen RA, Seeldrayers S, Marcus MA, Daemen JW, PeutzKootstra CJ, Buurman WA, Schurink GW, Ernest van Heurn LW: Autologous transplantation of ischemically injured kidneys in pigs. J Surg Res 2011, 171:844-850.

doi:10.1186/1479-5876-12-53

Cite this article as: Zhao et al:: Increased peripheral and local soluble FGL2 in the recovery of renal ischemia reperfusion injury in a porcine kidney auto-transplantation model. Journal of Translational Medicine 2014 12:53.

\section{Submit your next manuscript to BioMed Central and take full advantage of:}

- Convenient online submission

- Thorough peer review

- No space constraints or color figure charges

- Immediate publication on acceptance

- Inclusion in PubMed, CAS, Scopus and Google Scholar

- Research which is freely available for redistribution 